an completely gone: on her raiaing up the trunk, 80 as to tange her position for examination, I observed a large mass to start forwards in the centre of the sbdomen, where swelling then appeared, about the size of a child's head, but more elongated in shape, extending from the umbilicus to near the top of the pubis; the sides of the abdomen being at the same time considerably flattened and hard, whilst the swelling was softer, and gave a very resonant sound on percussion. This swelling immediately subsided on her resuming the horizontal posture, returning again on rising, and becoming still more prominent on assuming the erect posture. An examination of the abdomizal parietes, when she lay at rest in the horizontal posture, at once pointed out the cause: they were soft and flaccid; and along the course of the linea alba, from the umbilicus downwards, I found the two recti muscles quite separated from each other, the inner border of each being quite free and distinct, and the ends of the fingers readily introduced between them. This at once brought me to the conclusion that there was a separation or rupture along the linea alba, and that, during the act of rising or standing, the two recti muscles contracting forced out between their inner borders a large quantity of the intestines, which, covered by skin and peritoneum, formed the tumour of which this lady complained.

It seems to me most probable that this rupture along the linea alba must have occurred at her previous confinement, and that the gradual outward pressure of the intestines had greatly enlarged it. I advised her to have an abdominal bandage, with a large and strong piece of sole leather in front, so as to form a strong support in front: the bandage to be worn tolerably light, and to be used night and day. This wos the only treatment required. At about the end of twelre months, she reported herself quite well, and discontinued the bandage, but has since been obliged to resume it.

I have since seen two similar cases; one I saw in consultation with a medical gentleman, who had, up to the time of my visit, considered the case as ovarian.

6 Lever Street, Manchester, September 1854.

\section{CASE OF POISONING BY THE OIL OF BITTER ALMONDS: RECOVERY.}

By JOHN PURSELL, M.D., F.R.C.S.

J.D., four years of age, a fine grown boy, was brought to my residence at half-past twelve P.M., on Surday the first of Dec., 1850. He had swallowed about five minutes previously four or five drachms of the "oil of bitter almonds", the bottle containing which had been incautiously placed on the kitchen table shortly before, for the purpose of preparing the essential oil for pastry. The child observing his mother's attention to be temporarily engaged in preparing the family dinner, took hold of the bottle, and placing the neck in his mouth swallowed (as far as could be estimated from what remained in the bottle) the quantity specified above. Having hastily replaced the bottle on the table (after he had at length attracted the attention of his mother) he ran quickly up stairs, followed by his mother, who was alarmed at seeing him remove the bottle from his mouth. On reaching the passage, he staggered and fell on the floor apparently insensible. The father hearing the shrieks of his wife hastened down stairs, raised the little fellow up, and speedily conveyed him to my residence, distant about a hundred yards.

On seeing him, I found the following symptoms present. The countenance was very much flushed; the eyeballs were remarkably prominent, had a rolling motion, and nearly protruded from their sockets; the pupils were widely dilated and insensible to light; the pulse was full and strong, but slow; the breathing was stertorous; there was complete opiathotonos, and frequent convulsive action of the muscles of the face and neck. From the rigid contraction of the jow, I experienced some difficulty in administering a strong solution of the sulphate of sinc, the sction of which I excited by irritating the fauces with a feather. I adopted this expedient to gain time, while the stomach-pump was being prepared. This being procured, I speedily introduced the tube into the stomach (not until the little patient had nearly divided the tube with his teeth) and injected several portions of warm water, which returned with a good deal of undigested food, emitting strongly the characteristic odour of bitter almonds. I continued to throw in warm water until the fluid drawn up no longer presented the peculiar smell of the poison. Cold affusion was now resorted to, and continued for some time; brandy and water was administered, and repeated at frequent intervals, the patient having fallen into a state of collapse, mustard cataplasms were applied to the epigastrium and the whole length of the spine. On the establishment of reaction, castor oil was prescribed, which acted freely; and we soon had the satisfaction of observing returning consciousness, after persevering in our efforts for about four hours. In half an hour, the patient was sufficiently recovered to permit of his removal home by his parents, who anxiously awaited the issue.

I visited the little patient two hours afterwards; and was much gratified in observing that he had entirely recovered his accustomed animation and cheerfulness, after having swallowed so large a dose of the poison.

REMARS. This case affords an additional illustration of the necessity of prompt and decisive treatment, when available. There is no doubt that a successful issue was occasioned by the circumstance of my being at home, and in prompt attendance upon the little patient the moment he was brought in, and by the stomach being immediately emptied of the poison; three or four minutes' further delay would probably have rendered abortive all efforts to counteract the deadly effects of so active a poison, in consequence of its rapid absorption into the system.

It may not be unimportant to add that the preparation which the child obtained and swallowed from the bottle was the genuine and concentrated oil of bitter almonds, the father requiring the preparation in the conducting of his business as a capillaire maker and distiller, and preparer of compounds.

36, Harleyford Place, Kennington Park, Sept. 4th, 1854.

\section{A NEW FORM OF ASTRINGENT APPLICATION.}

By WILLIAM BAYES, M.D., Physician to the Brighton Dispensary.

Pere glycerine dissolves nearly its own weight of tannin, affording a very powerful local astringent application.

The solution of tannin in pure glycerine appears to me to supply a desideratum long felt, and capable of a great variety of useful applications.

The solvent property of glycerine over tannin allows us to form a lotion of any desirable strength, as the solution is readily miscible with water.

The solution of tannin in glycerine, in one or other of its strengths, is peculiarly applicable to many disorders of the mucous membrane, readily cubining with mucus, and forming a non-evaporisible coatiug over dry membranes; hence it may with benefit be applied to the mucous membranes of the eye and ear in many of its diseased conditions. It forms a most convenient application to the vaginal, u terine, urethral, or rectal membranes, where a strong and non-irritant astringent lotion is desired.

In local hæmorrhages, where the bleeding surface can easily be reached, it will prove very convenient, and may be applied either with a sponge or small brush.

The solution must be kept in the dark, and should not be prepared for any great length of time before used, or docomposition will occur.

It is singular that glycerine does not possess the me property towards gallic acid.

28 Old Steine, Brighton, September 1854. 